\title{
Locked nucleic acid inhibits amplification of contaminating DNA in real-time PCR
}

\author{
Lone Hummelshoj, Lars P. Ryder, Hans O. Madsen, and Lars K. Poulsen
}

BioTechniques 38:605-610 (April 2005)

\begin{abstract}
Locked nucleic acid $\left(L N A^{\circledR}\right)$ is a modified DNA with increased binding affinity for complementary DNA sequences. Our strategy was to use this property of LNA to inhibit undesired PCR amplification (e.g., from contaminating genomic DNA) in a cDNA-based assay. By placing a short complementary LNA sequence in intronic DNA, the aim was to inhibit the amplification of genomic DNA without affecting the amplification of reverse-transcribed spliced $m R N A$. LNA was designed to bind within intron 5 in the $x$-box binding protein 1 (XBP1) gene. An irrelevant LNA oligonucleotide served as a negative control. In both PCR and real-time PCR, the addition of LNA showed blocking of the amplification of genomic XBP1 but not cDNA XBP1. To test the effect of melting temperature ( $\left.T_{m}\right)$ on the LNA, we investigated the number of LNA nucleotides that could be replaced with DNA nucleotides and still retain the blocking activity. More than three DNA nucleotides reduced the LNA inhibition ability. The sequence specificity of the LNA was tested by investigating the number of LNA nucleotide mismatches permitted. The introduction of one mismatch maintained the inhibition of genomic amplification whereas two mismatches reduced the amplification. Our results show that LNA may be used to enhance the specificity of PCR by eliminating unwanted PCR products.
\end{abstract}

\section{INTRODUCTION}

Since the 1980s, there has been much focus on developing modified oligonucleotides for controlling gene expression, with the further purpose of being used as potential therapeutic agents for a wide variety of diseases. In 1998, Koshkin et al. $(1,2)$ and Obika et al. (3) were the first to describe one such class of nucleic acid analogues, the locked nucleic acids $\left(\mathrm{LNA}^{\circledR} \mathrm{s}\right)$. LNAs are ribonucleotides containing a methylene bridge that connects the $2^{\prime}$-oxygen of ribose with the $4^{\prime}$-carbon (Figure 1A). This bridge results in a locked 3'-endo conformation that reduces the conformational flexibility of the ribose. LNA bases are linked in the same phosphate backbone as DNA and RNA, allowing LNA oligomers to be introduced into DNA and RNA sequences. The introduction of LNA into a DNA oligomer improves the hybridization affinity for complementary sequences and increases the melting temperature $\left(\mathrm{T}_{\mathrm{m}}\right)$ by several degrees. Compared to DNA, the oligonucleotides containing LNA have an increased $\mathrm{T}_{\mathrm{m}}$ of $1^{\circ}-8^{\circ} \mathrm{C}$ per LNA nucleotide incorporated, depending on the position of the modified residues $(1,3-5)$.

To date, most work with LNA has dealt with the use of controlling gene expression, and attempts have been made to improve specificity and therapeutic efficacy $(6,7)$. Recently, only few studies have focused on the use of LNA in molecular methods. LNA has been found to be resistant to $5^{\prime}$ exonuclease activity of proofreading DNA polymerases and to be unable to function as primers in polymerase extension assays $(8,9)$. However, no studies have described the use of LNA as an inhibitor component in either PCR or real-time PCR. Real-time PCR is one of the most sensitive methods for the detection of low abundance mRNA. However, it is a complex technique, and there are substantial problems associated with its sensitivity, reproducibility, and specificity. One of the most serious drawbacks of this method is the amplification of false-positive products due to DNA contamination in the RNA samples, which can interfere with the quantification of mRNA. DNA contamination is particularly a problem when dealing with small amounts of RNA, where even a small amount of DNA might compete with the singlestranded cDNA and affect the reliability of real-time PCR.

The high $\mathrm{T}_{\mathrm{m}}$ values of LNA oligonucleotides prompted us to pursue the use of LNA as a specific inhibitor of genomic amplifications in PCR and real-time PCR, without affecting the amplification of the cDNA product (Figure 1, B and C). By placing a short LNA sequence in the intron of a gene, the goal was to block all genomic amplification due to the high-binding affinity of LNA. Throughout this study, we used 14-mer oligonucleotides that not only consisted of pure LNA, but also LNA/ DNA chimeras in order to investigate the effect of the $T_{m}$ on the LNA probe. We also studied the specificity of the LNA by introducing mismatches in the inhibitory LNA. As a model, we used the B-cell plasma cell marker $x$-box binding protein (XBP1) as the DNA and cDNA template, which is highly expressed in the B-lymphoma cell line U266. 
Table 1. List of Oligonucleotides Used in this Study

\begin{tabular}{|c|c|c|c|}
\hline Oligonucleotide & Sequence & $\begin{array}{l}T_{m} \\
\left({ }^{\circ} \mathbf{C}\right)\end{array}$ & $\begin{array}{l}\text { Genome } \\
\text { Position }\end{array}$ \\
\hline XBP1 Forward, real-time PCR & 5'-GGCGGTATTCAGTCTTCAGATTCA-3' & 64 & $2781-2804$ \\
\hline XBP1 Reverse, real-time PCR & 5'-GCATTTGAAGAACATGACTGGGT-3' & 64 & $3156-3178$ \\
\hline XBP1 Forward, PCR & 5'-CATGGATTCTGGCGGTATTCACT-3' & 65 & $2771-2793$ \\
\hline XBP1 Reverse, PCR & 5'-ACAGGTTCTTCCTTCACTGAGACAA-3' & 65 & $3441-3465$ \\
\hline LNA1 & 5'-AGAGAATAAAGCAG-3' & 82 & $1861-1874$ \\
\hline LNA2 & 5'-CAGATGAGGGTTGA-3' & 97 & 2886-2899 \\
\hline LNA2.3 & 5'-CAGATGAGGGTTGA-3' & 85 & 2886-2899 \\
\hline LNA2.6 & 5'-CAGATGAGGGTTGA-3' & 69 & $2886-2899$ \\
\hline LNA2.9 & 5'-CAGATGAGGGTTGA-3' & 63 & $2886-2899$ \\
\hline LNA2.12 & 5'-CAGATGAGGGTTGA-3' & 53 & 2886-2899 \\
\hline LNA2.1M & 5'-CAGATGACGGTTGA-3' & 95 & 2886-2899 \\
\hline LNA2.2M & 5'-CAGATGTCGGTTGA-3' & 93 & 2886-2899 \\
\hline Real-Time PCR probe & 5'-ATCCTGTTGGGCATTCTGGACAACTGG-3' & 70 & $3128-3154$ \\
\hline
\end{tabular}

\section{MATERIALS AND METHODS}

\section{DNA and RNA Isolation and Reverse Transcription}

DNA and RNA were isolated from the B-cell line U266 using the QIAamp ${ }^{\circledR}$ DNA Blood Mini Kit and the RNeasy ${ }^{\circledR}$ Mini Kit (both from Qiagen, Hilden, Germany), respectively. For quantifying DNA and mRNA, samples were diluted in TE buffer (10 mM Tris-HCl, $1 \mathrm{mM}$ EDTA, pH 7.4) and measured spectrophotometrically on a SmartSpec ${ }^{\mathrm{TM}} 3000$ spectrophotometer (Bio-Rad Laboratories, Hercules, CA, USA). One microgram of each RNA sample was immediately submitted to first-strand synthesis, and the remaining RNA was stored at $-80^{\circ} \mathrm{C}$. First-strand synthesis was performed as previously described (10) using SUPERSCRIPT TM II reverse transcriptase (Invitrogen, Carlsbad, CA, USA).

\section{Oligonucleotides}

DNA oligonucleotide primers were carefully designed to avoid selfcomplementarity and blasted for similar sequences. Primers were designed to bind within exon 4 and exon 5. PCR primers were chosen to yield products with a length of $695 \mathrm{bp}$ for genomic products and $381 \mathrm{bp}$ for mRNA products. For real-time PCR, the lengths of the genomic products were 398 and 84 bp for mRNA products.

All oligonucleotides containing LNA were obtained from Proligo (Boulder, CO, USA), while the unmodified DNA primers and TaqMan ${ }^{\circledR}$ probe (FAM) were purchased from MWG-Biotech AG (Ebersberg, Germany). The sequences of the oligonucleotides are shown in Table 1 . The $\mathrm{T}_{\mathrm{m}} \mathrm{s}$ were calculated using the Exiqon Tm prediction tool available online at www.lna-tm.com.

\section{PCR for Detection of XBP1}

A $10-\mu \mathrm{L}$ PCR containing $500 \mu \mathrm{M}$ each of dNTP, $50 \mathrm{mM}$ Tris, $15 \mathrm{mM}$
Figure 1. Experimental Design. (A) Chemical structure of LNA ${ }^{\circledR}$ and DNA monomer. Because of the 2'-C, 4'-C-oxymethylene-linked binding, the LNAs obtained increased stability and higher $\mathrm{T}_{\mathrm{m}}$ compared to DNA. (B-C) Inhibitory LNA strategy. XBP1 consists of five exons. Purified mRNAs may contain DNA contamination and, in typical real-time PCR, give rise to unwanted DNA PCR products that are indistinguishable from cDNA PCR products. (C) The use of a specific LNA blocker inhibits unwanted DNA amplification without affecting the amplification of cDNA. LNA, locked nucleic acid; $\mathrm{T}_{\mathrm{m}}$, melting temperature. 
ammonium sulfate, $\mathrm{pH} 9.3,5 \mathrm{mM}$ $\mathrm{MgCl}_{2}, 0.02 \%$ dimethyl sulfoxide (DMSO), $200 \mathrm{nM}$ of each primer, and $0.5 \mathrm{U}^{\text {AccuTaq }}{ }^{\mathrm{TM}} \mathrm{LA}$ DNA polymerase (Sigma, St. Louis, MO, USA) was mixed. A total of 35 amplification cycles were performed in a GeneAmp ${ }^{\circledR}$ PCR System 9700 Thermal Cycler (Applied Biosystems, Foster City, CA, USA) consisting of a heating step of $94^{\circ} \mathrm{C}$ for $15 \mathrm{~s}$, followed by annealing at $56^{\circ} \mathrm{C}$ for $30 \mathrm{~s}$, and subsequent extension at $68^{\circ} \mathrm{C}$ for $60 \mathrm{~s}$. Prior to amplification, the reaction mixture was held for
$30 \mathrm{~s}$ at $98^{\circ} \mathrm{C}$, and the last incubation continued for $10 \mathrm{~min}$. PCR products were separated on a $3 \%$ agarose gel and imaged on a GeneGenius ${ }^{\mathrm{TM}}$ GelScanner (Syngene, Cambridge, UK).

\section{Real-Time PCR}

A $10-\mu \mathrm{L}$ real-time PCR containing $1 \mu \mathrm{M}$ of each primer, $200 \mathrm{nM}$ probe, and TaqMan Universal PCR MasterMix (including AmpliTaq ${ }^{\circledR}$ Gold, AmpErase ${ }^{\circledR}$ UNG, and dNTPs with dUTP and optimized buffer

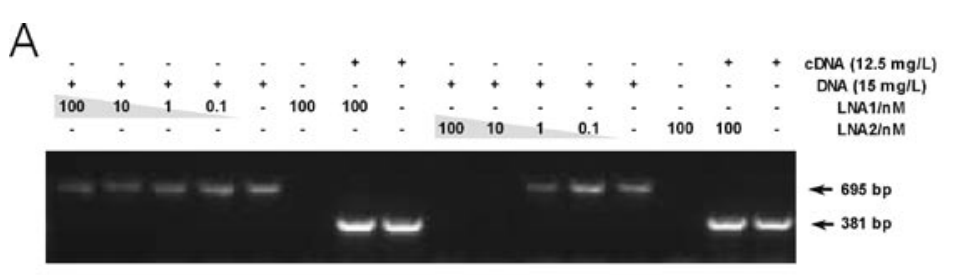

B
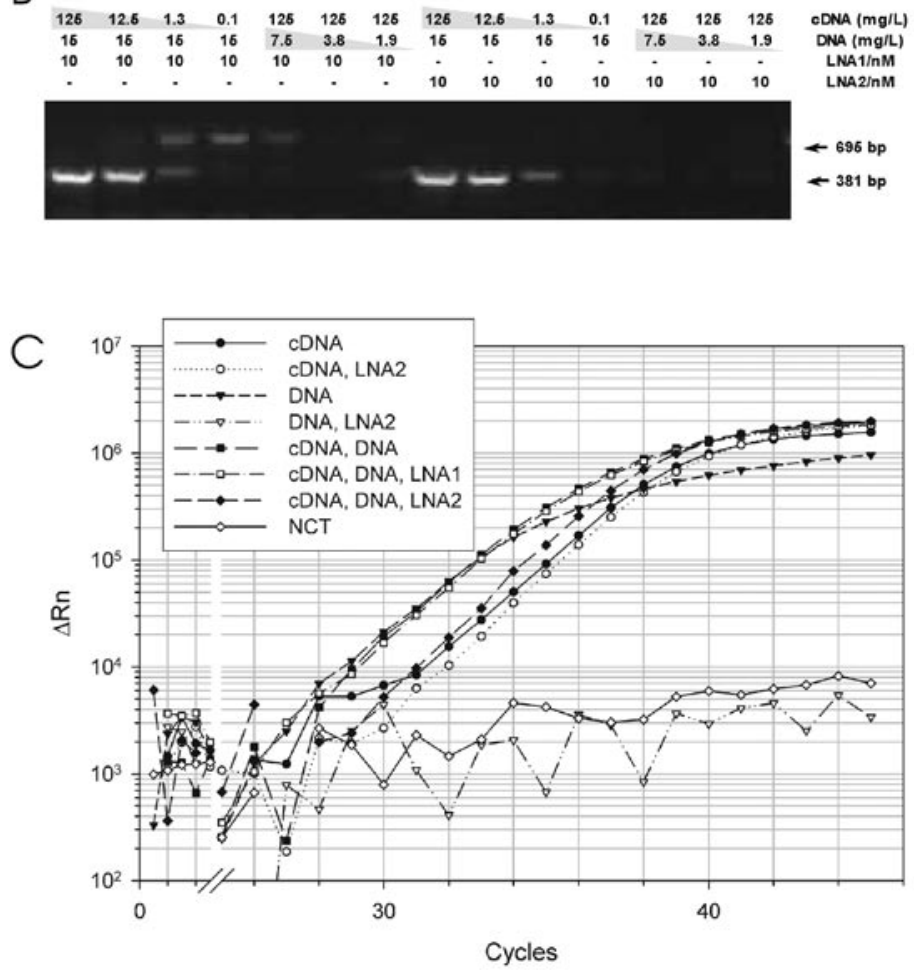

Figure 2. The effect of LNA was investigated in PCR and real-time PCR. The inhibitory effect of LNA on XBP1 amplification was tested using (A and B) PCR and (C) real-time PCR. (A) Irrelevant LNA (LNA1) and intron 5-specific LNA (LNA2) were tested in a dose-response manner, in reactions where template material was either DNA $(15 \mathrm{mg} / \mathrm{L})$ or cDNA $(12.5 \mathrm{mg} / \mathrm{L})$. The arrow at $695 \mathrm{bp}$ represents genomic amplification of XBP1 whereas the arrow at 381 bp represents cDNA amplification. (B) At a fixed LNA concentration of $10 \mathrm{nM}, \mathrm{PCR}$ was performed on DNA and cDNA, diluted, and mixed as shown. (C) LNA1 and LNA2 were tested on DNA $(15 \mathrm{mg} / \mathrm{L})$ and cDNA $(0.1 \mathrm{mg} / \mathrm{L})$ using real-time PCR. DNA, cDNA, or a combination of the two were tested with or without LNA1 and LNA2 (for simplification, only data with DNA/cDNA are shown for LNA1). One representative experiment of four is shown. LNA, locked nucleic acid; NTC, no template control. components; Applied Biosystems) was mixed. The expression of XBP1 was determined using real-time PCR performed on an ABI PRISM ${ }^{\circledR} 7700$ Sequence Detection System (Applied Biosystems). A total of 45 amplification cycles were performed by a heating step of $95^{\circ} \mathrm{C}$ for $15 \mathrm{~s}$, followed by annealing at $60^{\circ} \mathrm{C}$ for $1 \mathrm{~min}$. Prior to amplification, the reaction mixture was held for $2 \mathrm{~min}$ at $50^{\circ} \mathrm{C}$, followed by 10 min at $95^{\circ} \mathrm{C}$. The results were analyzed using sodium dodecyl sulfate (SDS 1.7; Applied Biosystems). Every sample was run in triplicate.

\section{RESULTS}

This study was undertaken to investigate whether LNA could be used for specific inhibition of genomic DNA amplification of XBP1 without affecting the amplification of specific cDNA. We developed and optimized a PCR and a real-time PCR for the determination of XBP1.

\section{Selection of Optimal Primers and Probe for the XBP1 PCR and Real- Time PCR}

XBP1 PCR and real-time PCR were developed and optimized with separately purified cDNA and genomic DNA from the plasma cell line U266 as a template. The small XBP1 products in the real-time PCR could not be visualized on an agarose gel because the size of the band was the same length as the primer-dimer bands. We therefore designed a PCR with longer products to be able to visualize the two bands, representing genomic and mRNA XBP1, respectively.

Various concentrations of primers (200, 500, and $1000 \mathrm{nM}$ ), TaqMan probes $(50,100$, and $200 \mathrm{nM}$ ), and template DNA or cDNA were tested. The concentrations of primers and probes giving the highest fluorescence intensity and lowest threshold cycle were selected as follows: $200 \mathrm{nM}$ of both primers for PCR, $1000 \mathrm{nM}$ of both primers for real-time PCR, $200 \mathrm{nM} \mathrm{XBP1}$ probe, 15 $\mathrm{mg} / \mathrm{L}$ DNA, or $12.5 \mathrm{mg} / \mathrm{L}$ cDNA, unless otherwise noted. A PCR product of 695 bp resulted from the amplification of genomic XBP1 whereas amplification 
of the spliced cDNA resulted in a PCR product of $381 \mathrm{bp}$. In illustrations of the real-time PCR results, a cut-off value of $\Delta \mathrm{Rn}$ was set at $10^{2}$. Points below this value were considered background.

\section{Inhibition of Genomic XBP1 Amplification with LNA Probe}

In order to inhibit the amplification of unwanted genomic DNA PCR products, an LNA probe was designed to bind within intron 5 (LNA2), the intron between the two exons where the primers were located. An LNA probe specific for intron 2 (LNA1), an intron placed approximately $1000 \mathrm{bp}$ upstream of the primer area, was used as a negative control (Figure 1).

LNAs were diluted 10-fold from 100 to $0.1 \mathrm{nM}$ and tested in PCR and realtime PCR using cDNA $(12.5 \mathrm{mg} / \mathrm{L})$ and DNA $(15 \mathrm{mg} / \mathrm{L})$ as templates (Figure 2A). LNA2 was able to inhibit the amplification of DNA XBP1 in a dosedependent manner. At LNA concentrations above $10 \mathrm{nM}$, a complete inhibition was observed, whereas only a partial inhibition was observed at $1 \mathrm{nM}$. By lowering the LNA2 concentration to $0.1 \mathrm{nM}$, the inhibitory effect disappeared. No inhibition was observed when using the LNA1 negative control. For cDNA PCR, neither LNA1 nor LNA2 had any inhibitory effect in any of the tested concentrations. Only the effect of $100 \mathrm{nM}$ LNA concentrations is shown in Figure 2A.

In an attempt to model the theoretic problem with DNA contamination in cDNA samples, we separately mixed prepared DNA with cDNA samples. In the sample containing a mixture of DNA and cDNA (15.0 to $12.5 \mathrm{mg} / \mathrm{L}$ ), the cDNA band almost completely dominated the amplification, and the genomic band was very faint, if visible at all. Therefore we mixed DNA with cDNA in 2-fold dilutions of DNA (15.0 to $1.9 \mathrm{mg} / \mathrm{L}$ ) and 10 -fold dilutions of cDNA (125 to $0.1 \mathrm{mg} / \mathrm{L}$; Figure $2 \mathrm{~B})$. In competition with the more favorable cDNA amplification, the optimal DNA concentration was $15 \mathrm{mg} / \mathrm{L}$ whereas cDNA had to be diluted to $1.3 \mathrm{mg} / \mathrm{L}$. The addition of LNA2 to this mixture completely inhibited DNA amplification without affecting the amplification of cDNA XBP1, indicating a complete blocking of genomic amplification.

We then investigated the LNAs in real-time PCR. Reactions with DNA, cDNA, or a combination of the two were tested with LNA1 or LNA2. Without LNA or with LNA1, no inhibition of genomic amplification was observed (Figure 2C). For simplification of the figure in reactions with LNA1, only the mixture with DNA/ cDNA is shown. Both combinations of LNA1/DNA and LNA1/cDNA were similar to the reaction without LNA, showing no inhibition of the reaction (data not shown), which indicated that the observed inhibition is specific and not due to an effect of any LNA present. The addition of LNA2 completely inhibited the DNA XBP1 amplification without affecting the amplification of cDNA XBP1. These data indicate that LNA2 is able to act as a specific inhibitor of the amplification of genomic DNA, without affecting cDNA amplification, in both PCR and real-time PCR.

\section{Inhibition of Genomic XBP1 Amplification with Chimeric DNA/LNA Probes}

To investigate the influence of $\mathrm{T}_{\mathrm{m}}$ on LNA, we introduced $3,6,9$, or 12 DNA nucleotides in the 14-mer LNA2 probe (Table 1). The LNA/DNA probes LNA2.3, LNA2.6, LNA2.9, and LNA2.12 were investigated in PCR and real-time PCR with DNA $(15 \mathrm{mg} / \mathrm{L})$ and cDNA $(0.1 \mathrm{mg} / \mathrm{L})$ as templates. None of the modified LNA nucleotides were able to inhibit the genomic amplification at a concentration of $10 \mathrm{nM}$ (data not shown). By raising the LNA

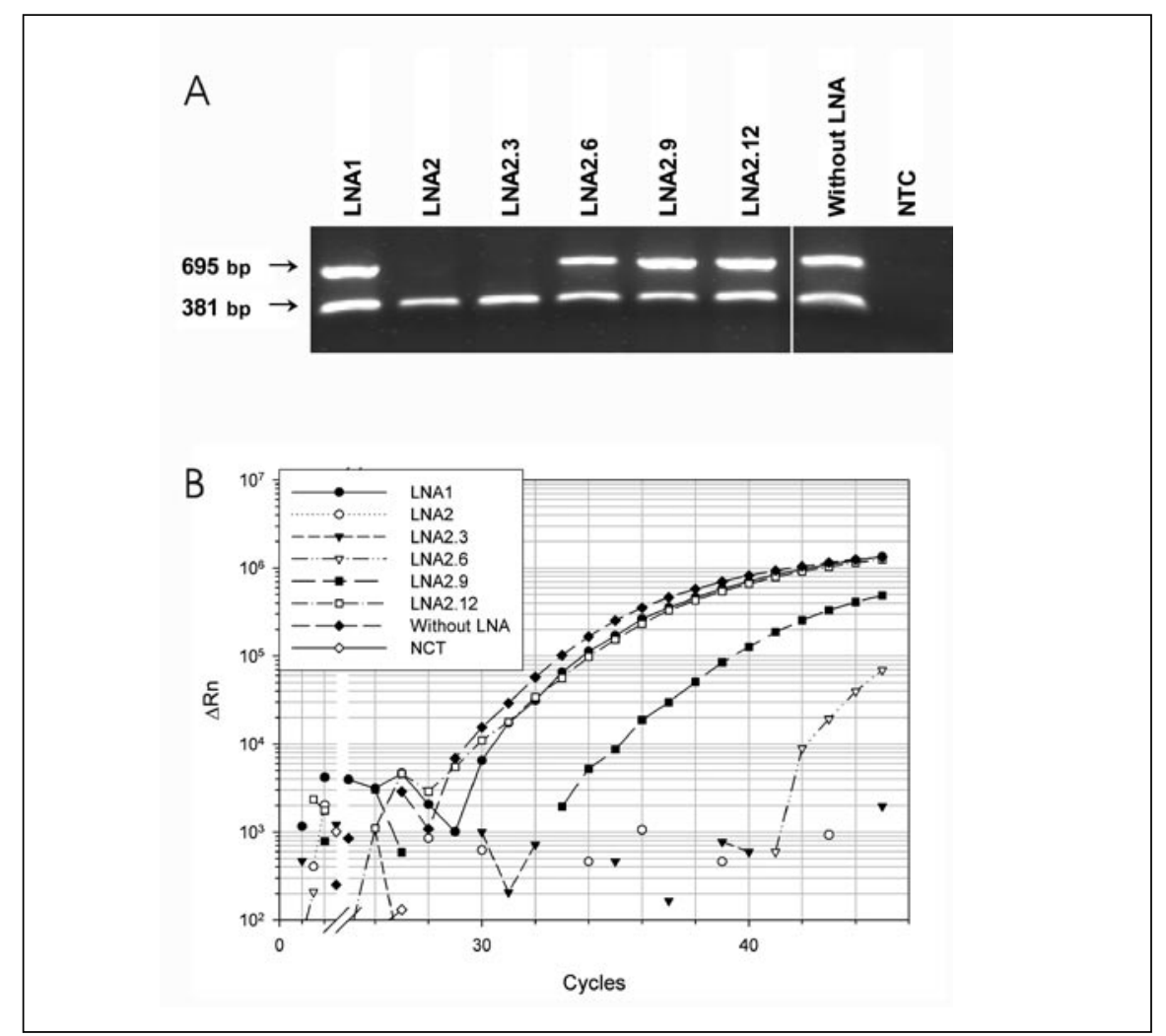

Figure 3. The effect of introducing DNA nucleotides in LNA2 was tested using PCR and real-time PCR. The effect of introducing DNA nucleotides in the inhibitory LNA2 sequence was tested in (A) PCR and (B) real-time PCR. (A) Three (LNA2.3), six (LNA2.6), nine (LNA2.9), or 12 (LNA2.12) LNA nucleotides were replaced in the 14-mer LNA2 by DNA and tested in concentrations of $100 \mathrm{nM}$ (data not shown) and $1000 \mathrm{nM}$ on DNA $(15 \mathrm{mg} / \mathrm{L})$ and cDNA $(0.1 \mathrm{mg} / \mathrm{L})$. The LNA1 was used as a control. The arrow at $695 \mathrm{bp}$ represents genomic amplification of XBP1 whereas the arrow at $381 \mathrm{bp}$ represents cDNA amplification. (B) The same oligonucleotides as described above were tested on DNA in realtime PCR. No inhibition was observed when using the modifications with cDNA as a template (data not shown). One representative experiment out of three is shown. LNA, locked nucleic acid; NTC, no template control. 
concentration to 100 and $1000 \mathrm{nM}$, the LNA2.3 with 3 DNA substitutions was the only one of the LNAs able to inhibit PCR (Figure 3A; data shown only for $1000 \mathrm{mM}$ ), although only $1000 \mathrm{nM}$ LNA2.3 produced a $100 \%$ inhibition.

In real-time PCR, LNA2.3 completely inhibited the amplification at both 100 and $1000 \mathrm{nM}$ (data shown only for $1000 \mathrm{nM}$ ), and LNA2.6 (with 6 DNA substitutions) also resulted in a partly inhibitory effect. In addition, LNA2.9 showed an inhibitory effect in the two LNA concentrations, although it was less than LNA2.6. For every addition of 3 DNA nucleotides, amplification curves right-shifted approximately 6-7 cycles. Neither of the probes inhibited cDNA amplification (data not shown). These data indicate the importance of $T_{m}$ for LNA as an inhibitor.

\section{Inhibition of Genomic XBP1 Amplification with LNA Mismatch Probes}

To investigate the sequence specificity of the LNA probes, we introduced one or two mismatches into LNA2 (Table 1). The LNA probes LNA2.1M ( $\mathrm{G}$ to $\mathrm{C}$ ) and LNA2.2M ( $\mathrm{G}$ to $\mathrm{C}$ and A to T) were tested in PCR and realtime PCR as described above. Only LNA2.1M was able to block genomic amplification in PCR and only at 1000 $\mathrm{nM}$ (Figure 4A, data shown only for $1000 \mathrm{mM}$ ). An inhibitory effect was observed for both mismatch oligonucleotides, at both 100 and 1000 mM LNA, in real-time PCR (Figure 4B, data shown only for $1000 \mathrm{mM}$ ), although LNA2.1M resulted in a higher inhibition compared to LNA2.2M. These data indicate that the LNAs have to be extremely specific to bind tightly enough to the intron and maintain blocking activity.

\section{DISCUSSION}

Discrimination between the amplification of mRNA and contaminating genomic DNA is a common problem when performing real-time PCR. Several studies have been made in an attempt to avoid the amplification of DNA contaminations; for example, by the use of DNase. But even after DNase treatment of the samples, DNA fragments may still remain (11). Furthermore, treatment with DNase and the subsequent inactivation of the enzyme may also cause RNA loss due to the presence of divalent cations in the buffer and/or due to the phenol/ chloroform extraction (12), which is particularly a problem when dealing with low amounts of RNA. This study was undertaken to investigate whether LNA could prove a useful component in real-time PCR by inhibiting the amplification of contaminated genomic DNA. We tried to determine whether LNA was able to bind strong enough to intronic DNA, due to the high $\mathrm{T}_{\mathrm{m}}$, resulting in blocking of the polymerase transcription.

We first analyzed the effect of intron 5-specific LNA (LNA2) on PCR and real-time PCR. LNA2 showed a specific doseresponse inhibition of DNA amplification without affecting the amplification of cDNA, indicating a specific blocking of DNA amplification. LNA1 showed no inhibition, indicating that LNA2 inhibits specifically and not as a result of a bystander effect.

Secondly, we examined the effect of introducing DNA nucleotides into the LNA2 sequence, creating chimeric DNA/LNA and thereby reducing the $\mathrm{T}_{\mathrm{m}}$ of the LNA. For every 3 DNA nucleotides substituted, the $T_{m}$ was reduced to between $6^{\circ}$ and $16^{\circ} \mathrm{C}$. In agreement with the literature $(1,3-5)$, LNA oligonucleotides increased the $\mathrm{T}_{\mathrm{m}}$ of the sequence by $1^{\circ}-8^{\circ} \mathrm{C}$ per modified nucleotide. As the $\mathrm{T}_{\mathrm{m}}$ of the LNA decreased, the inhibitory effect was reduced. These data illustrate that the inhibitory effect is extremely dependent on the $\mathrm{T}_{\mathrm{m}}$ and the ability of LNA to bind strongly to the genomic intron. LNA has been described as being able to resist polymerase exonuclease activity (9), which is probably a property necessary for this efficient inhibitory function.

In our study, we used two different methods, PCR and real-time PCR, which are performed with different primers, enzymes, amplification cycles, and DNA concentrations because each parameter was optimized for the specific method. Our results showing that LNAs were able to induce a higher inhibition in real-time PCR compared to PCR could be explained because of the different assay conditions. We can therefore not expect the same amount of inhibition in both methods, but the tendency of inhibition in the two assays is the same.

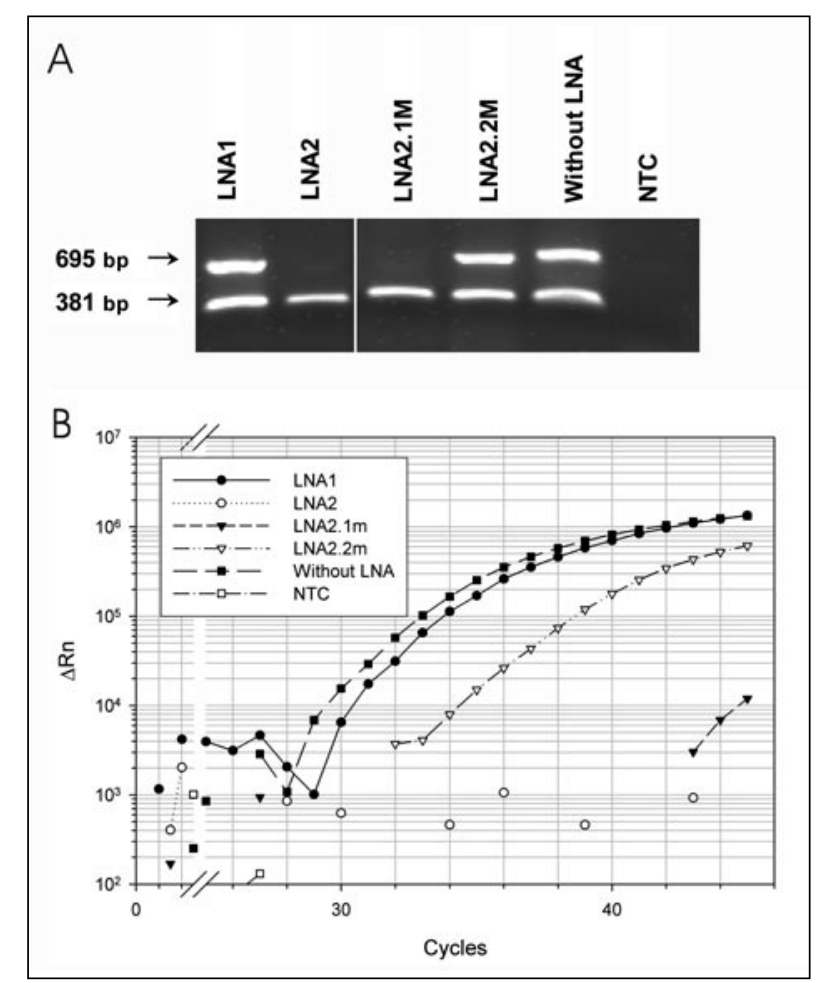

Figure 4. The effect of introducing a mismatch in LNA2 was tested in PCR and real-time PCR. The effect of introducing a mismatch in the inhibitory LNA2 was tested in (A) PCR and (B) real-time PCR. (A) One (LNA2.1M) or two (LNA2.2M) mismatches were introduced into LNA2 and tested in concentrations of $100 \mathrm{nM}$ (data not shown) and $1000 \mathrm{nM}$ on DNA and cDNA. LNA1 was used as a control. The arrow at $695 \mathrm{bp}$ represents genomic amplification of XBP1 whereas the arrow at $381 \mathrm{bp}$ represents cDNA amplification. (B) The same oligonucleotides as described above were tested on DNA in real-time PCR. No inhibition was observed when using the modifications with cDNA as a template (data not shown). One representative experiment out of three is shown. LNA, locked nucleic acid; NTC: no template control. 
Thirdly, we investigated the importance of sequence specificity by the introduction of one or two mismatches into LNA2. For a complete inhibition of DNA amplification, no more than one mismatch was allowed, indicating a highly specific inhibition. This high specificity allows LNA to be used in not only the selection between DNA and RNA, but also in selecting allelic variants, haplotypes, or somatic mutations as shown by Ugozzoli et al. (8) using LNA for allelic discrimination. Furthermore, LNA might be used in discriminating between alternatively spliced mRNA isoforms, which involves methodological problems analogous to those addressed in this work.

Not only do LNAs offer the highaffinity binding, the fact that their synthesis and physical properties closely resemble those for DNA makes it is easy to design and produce. It should also be mentioned that in a previous study we briefly tested another low-expressed gene, the $\beta \mathrm{t}$ gene in the human FceRI (13). As for XBP1, we found that LNAs were capable of inhibiting chromosomal amplification without affecting the cDNA amplification.

In conclusion, this study describes the development of a method for eliminating unwanted genomic amplification in PCR and real-time PCR by the use of LNA as a specific inhibitor. We showed that it is specific in inhibiting genomic DNA amplification without affecting cDNA amplification.

For a complete inhibition of genomic XBP1, the LNA probe must consist of mainly LNA, and no more than one mismatch is allowed. This might differ when working with other real-time PCR assays, and a titration would be necessary when designing LNA for other assays. This method could bring about major improvement particularly in real-time PCR where it may not be possible to discriminate between cDNA and genomic DNA amplification. LNA would be useful by enhancing the specificity of the assay by eliminating false-positive genomic amplification and is particularly useful in amplifications dealing with low abundant mRNA.

\section{COMPETING INTERESTS STATEMENT}

The authors declare no competing interests.

\section{REFERENCES}

1.Koshkin, A.A., S.K. Singh, P. Nielsen, V.K. Rajwanshi, R. Kumar, M. Meldgaard, C.E. Olsen, and J. Wengel. 1998. LNA (locked nucleic acids): synthesis of the adenine, cytosine, guanine, 5-methylcytosine, thymine and uracil bicyclonucleside monomer, oligomerisation and unprecedented nucleic acid recognition. Tetrahedron 54:3607-3630.

2.Koshkin, A.A., V.K. Rajwanshi, and J. Wengel. 1998. Novel convenient syntheses of LNA [2.2.1]bicyclo nuclesides. Tetrahedron Lett. 39:4381-4584.

3.Obika, S., D. Nanbu, Y. Hari, J.A.K. Morio, T. Doi, and T. Imanishi. 1998. Stability and structural features of the duplexes containing the nucleoside analogues with a fixed $\mathrm{N}$-type conformation, $2^{\prime}-\mathrm{O}, 4^{\prime}-C$-methyleneribonucleosides. Tetrahedron Lett. 39:5401-5404.

4.Braasch, D.A and D.R. Corey. 2001. Locked nucleic acid (LNA): fine-tuning the recognition of DNA and RNA. Chem. Biol. 8:1-7.

5.Wang, G., E. Gunic, J. Girardet, and V. Stoisavljevic. 1999. Conformationally locked nucleosides. Synthesis and hybridization properties of oligodeoxynucleotides containing 2'-,4'-C-bridged $2^{\prime}$-deoxynucleosides. Bioorg. Med. Chem. Lett. 9:1147-1150.

6.Petersen, M. and J. Wengel. 2003. LNA: a versatile tool for therapeutics and genomics. Trends Biotechnol. 21:74-81.

7.Wahlestedt, C., P. Salmi, L. Good, J. Kela, T. Johnsson, T. Hökfelt, C. Broberger, and F. Porreca. 2000. Potent and nontoxic antisense oligonucleotides containing locked nucleic acids. Proc. Natl. Acad. Sci. USA 97:5633-5638

8.Ugozzoli, L.A., D. Latorra, R. Pucket, K. Arar, and K. Hamby. 2003. Real-time genotyping with oligonucleotides probes containing locked nucleic acids. Anal. Biochem. 324:143-152.

9.Giusto, D.A.D and G. King. 2004. Strong positional preference in the interaction of LNA oligonucleotides with DNA polymerase and proofreading exonuclease activities: implications for genotyping assays. Nucleic Acids Res. 32:e32.

10.Glue, C., J.P. Hansen, P. Schjerling, T. Jinquan, and L.K. Poulsen. 2002. LPS-induced cytokine production in the monocytic cell line THP-1 determined by multiple quantitative competitive PCR (QC-PCR). Scand. J. Clin. Lab. Invest. 62:405-412.

11.Ivarsson, K. and B. Wiejdegard. 1998. Evaluation of the effects on DNase treatment on signal specificity in RT-PCR and in situ RT-PCR. BioTechniques 25:630-638.

12. Wiame, I., S. Remy, R. Swennen, and L. Sági. 2000. Irreversible heat inactivation of DNase I without RNA degradation. BioTechniques 29:252-256.

13.Jensen, B.M., S. Dissing, P.S. Skov, and
L.K. Poulsen. A comparative study of the FceRI molecule on human mast cell and basophil cell lines. Int. Arch. Allergy Immunol. (In press).

Received 5 July 2004; accepted 27 September 2004.

Address correspondence to:

Lone Hummelshoj

National University Hospital

Laboratory of Medical Allergology

Allergy Clinic 7551

Blegdamsvej 9, 2100 Copenhagen O, Denmark e-mail:l.hummelshoj@rh.dk 